\title{
APLIKASI METODE SIMPLEKS PADA OPTIMALISASI BIAYA BAHAN BAKU (STUDI KASUS: UKM NAJMAH KLAPPERTART)
}

\author{
D. Damayanti ${ }^{1}$, A. I. Jaya ${ }^{2}$, dan Resnawati ${ }^{3}$ \\ 1,2,3 Program Studi Matematika Jurusan Matematika \\ Fakultas Matematika dan IImu Pengetahuan Alam Universitas Tadulako \\ Jalan Sukarno-Hatta Km. 9 Palu 94118, Indonesia \\ 1dftdmyt@gmail.com, 2jayaindraagus@gmail.com, 3r35n4w4t1@gmail.com
}

\begin{abstract}
The purpose of this research is to obtain an the optimal production costs of Klappertart based on the basic ingredients comparing the production cost of Klappertart in Najmah Klappertart with production costs using the simplex method. The result showed that the optimal costs is Rp.931.097,-- This result is equal to the total cost of klappertart by SMEs Najmah Klappertart, so it can be concluded that the cost of production klappertart based on the basic ingredients on SMEs Najmah Klappertart were optimal.
\end{abstract}

Keywords : : Optimal Cost, Basic Ingredients, Production Costs. (A-Z), Simplex Method

\section{ABSTRAK}

Penelitian ini bertujuan untuk mendapatkan biaya produksi klappertart yang optimal berdasarkan bahan baku pembuatannya dan membandingkan biaya produksi klappertart di Najmah Klappertart dengan biaya produksi menggunakan metode simpleks. Hasil penelitian memberikan biaya optimal sebesar Rp. 931.097,- . Biaya ini sama dengan total biaya pembuatan klappertart oleh UKM Najmah Klappertart. Berdasarkan hasil penelitian tersebut dapat disimpulkan bahwa biaya produksi klappertart berdasarkan bahan baku pembuatannya pada UKM Najmah Klappertart sudah optimal.

Kata Kunci : Biaya Optimal, Bahan Baku, Biaya Produksi, Metode simpleks 


\section{PENDAHULUAN}

\subsection{Latar Belakang}

Situasi perekonomian pada zaman sekarang telah menyebabkan semakin ketatnya persaingan yang timbul di antara usaha-usaha rumahan yang berupaya untuk bertahan. Kondisi ini menyebabkan banyak perusahaan berlomba untuk menjadi yang terdepan dalam bidangnya. Sehingga setiap perusahaan harus mengembangkan dan meningkatkan kinerja agar dapat mencapai efektivitas dan efiensi terutama pada biaya produksi dan pengendalian bahan baku. Biaya produksi merupakan salah satu bagian dari langkah-langkah intern yang dilakukan perusahaan dalam usaha meningkatkan efisiensi. Permasalahan biaya produksi dan pengendalian bahan baku merupakan bagian penting dalam sektor produksi yang perlu dioptimalkan.

Banyak metode yang dapat dipakai untuk mengoptimalkan biaya produksi. Salah satu metode yang dapat digunakan untuk menyelesaikan masalah optimalisasi solusi optimal adalah dengan metode simpleks. Metode Simpleks merupakan suatu metode yang secara sistematis dimulai dari suatu pemecahan dasar ke pemecahan dasar lainnya yang dilakukan berulang-ulang sehingga akhirnya tercapai suatu pemecahan dasar yang optimum dan pada setiap langkahnya akan menghasilkan suatu nilai dari fungsi tujuan (Indrawati, 2012).

Salah satu usaha rumahan yang bergerak dalam bidang pangan yaitu klapertart. Klappertart merupakan kue atau makanan yang terbuat dari kue yang bercambur potongan kelapa yang di atasnya ditutupi oleh putih telur yang di kocok terlebih dahulu. Salah satu usaha kelas menengah rumahan yang bergerak dalam produksi klappertart yang berada di Palu yaitu Najmah Klappertart. Najmma Klappertart memproduksi tujuh jenis varian klappertart. Namun dalam penjualannya Najma Klappertart mematok harga yang cukup tinggi untuk satu buah klappertart. Sedangkan harga penjualan yang tinggi dapat mempengaruhi jumlah permintaan produk klapertart. Sehingga pada penelitian ini, penulis ingin mengetahui apakah dengan mengoptimalkan biaya bahan baku dapat menekan harga jual pada penjualan klappertart . Oleh sebab itu, perlu adanya optimalisasi biaya produksi berdasarkan bahan baku agar biaya pengeluaran perusahaan tersebut dapat ditekan seefisien mungkin.

Berdasarkan uraian yang dikemukakan di atas maka penulis tertarik melakukan penelitian dengan judul "Aplikasi Metode Simpleks pada Optimalisasi Biaya Bahan Baku (Studi Kasus: UKM Najmah Klappertart)". 


\subsection{Rumusan Masalah}

Dari latar belakang di atas, maka diperoleh rumusan masalah sebagai berikut:

1. Bagaimana cara mengelola biaya produksi agar bisa optimal dengan menggunakan metode simpleks?

2. Apakah biaya produksi Klappertart di Najmah Klappertart berdasarkan bahan baku pembuatannya sudah optimal?

\subsection{Batasan Penelitian}

1. Data yang digunakan adalah bahan baku selama setiap produksi.

2. Hasil perhitungan yang terdapat pada penjualan klappertart di Najmah Klappertart sama dengan hasil pada penerapan metode simpleks.

\section{METODE PENELTIAN}

Penelitian dilakukan sesuai prosedur di bawah ini:

1. Melakukan studi pustaka dengan mengumpulkan materi dari buku-buku, artikel atau jurnal yang di dapat dari perpustakaan dan perpustakaan online.

2. Menganalisa masalah

3. Melakukan studi lapangan

4. Pengumpulan data

5. Pembentukan model matematika dengan menentukan variabel keputusan, fungsi tujuan yang diambil dari biaya produksi dan fungsi kendala yang diambil dari kapasitas produksi, persediaan bahan baku dan komposisi bahan baku.

6. Penyelesaian menggunakan metode simpleks secara manual dan menggunakan software $Q M$ For Windows

7. Menganalisis.

8. Hasil

\section{HASIL DAN PEMBAHASAN}

\subsection{Hasil Penelitian}

Pada pengumpulan data, telah diperoleh data tentang biaya produksi klappertart, kapasitas produksi klappertart, jumlah persediaan bahan pembuatan klappertart, jumlah klappertart yang dipesan, serta data komposisi bahan tiap unit klappertart. Semua data yang diambil berdasarkan tiap periode produksi. Selanjutnya data-data tersebut nantinya akan dijadikan alat bantu untuk membuat suatu model matematika dalam bentuk program linier yang akan diselesaikan menggunakan metode simpleks dan juga software QM For Windows sehingga akan dihasilkan suatu output yang memberikan keterangan nilai optimal dari permasalahan yang ada. Datanya dapat dilihat pada Tabel 1 - 5 . 
Tabel 1 : Tabel Biaya Produksi

\begin{tabular}{|c|l|c|}
\hline No. & \multicolumn{1}{|c|}{ Varian Klappertart } & Biaya Produksi \\
\hline 1. & Klappertart Basah Keju & Rp. $3.216,36$ \\
\hline 2. & Klappertart Basah Durian & Rp. $3 \cdot 244,14$ \\
\hline 3. & Klappertart Basah Cokelat Oreo & Rp. $2.994,14$ \\
\hline 4. & Klappertart Basah Original & Rp. $3.435,53$ \\
\hline 5. & Klappertart Kering Keju & Rp. $18.111,14$ \\
\hline 6. & Klappertart Kering Kismis & Rp. $19.968,28$ \\
\hline 7. & Klappertart Kering Original & Rp. $19.238,28$ \\
\hline
\end{tabular}

(Sumber: Dedy Sutrisno, 2016)

Tabel 2 : Tabel Kapasitas Produksi

\begin{tabular}{|c|l|l|}
\hline No. & Varian Klappertart & $\begin{array}{c}\text { Kapasitas Produksi } \\
\text { (buah) }\end{array}$ \\
\hline 1. & Klappertart Basah Keju & 72 buah \\
\hline 2. & Klappertart Basah Durian & 72 buah \\
\hline 3. & Klappertart Basah Cokelat Oreo & 72 buah \\
\hline 4. & Klappertart Basah Original & 72 buah \\
\hline 5. & Klappertart Kering Keju & 7 buah \\
\hline 6. & Klappertart Kering Kismis & 7 buah \\
\hline 7. & Klappertart Kering Original & 7 buah \\
\hline
\end{tabular}

(Sumber: Dedy Sutrisno, 2016)

Tabel 3 : Tabel Persediaan Bahan Baku

\begin{tabular}{|c|l|c|}
\hline No. & Jenis bahan Baku & Persedian Bahan Baku (gr) \\
\hline 1. & Tepung Terigu & $4.000 \mathrm{gr}$ \\
\hline 2. & Susu & $3.600 \mathrm{gr}$ \\
\hline 3. & Kelapa Muda & $8.800 \mathrm{gr}$ \\
\hline 4. & Telur & $2.400 \mathrm{gr}$ \\
\hline 5. & Mentega & $4.000 \mathrm{gr}$ \\
\hline 6. & Gula & $8.000 \mathrm{gr}$ \\
\hline 7. & Garam & $250 \mathrm{gr}$ \\
\hline 8. & Vanili & $75 \mathrm{gr}$ \\
\hline 9. & Tepung Maizena & $5.100 \mathrm{gr}$ \\
\hline 10. & Keju & $360 \mathrm{gr}$ \\
\hline
\end{tabular}




\begin{tabular}{|c|l|c|}
\hline 11. & Durian & $1.000 \mathrm{gr}$ \\
\hline 12. & Cokelat Oreo & $270 \mathrm{gr}$ \\
\hline 13. & Kismis & $500 \mathrm{gr}$ \\
\hline 14. & Kenari & $500 \mathrm{gr}$ \\
\hline 15. & Kayu Manis & $500 \mathrm{gr}$ \\
\hline
\end{tabular}

(Sumber: Dedy Sutrisno, 2016)

Tabel 4 : Tabel Komposisi Bahan Baku

\begin{tabular}{|c|c|c|c|c|c|c|c|c|}
\hline \multirow{2}{*}{ No. } & \multirow{2}{*}{$\begin{array}{c}\text { Bahan } \\
\text { Baku }\end{array}$} & \multicolumn{4}{|c|}{ Klappertart Basah (gr) } & \multicolumn{3}{|c|}{ Klappertart Kering (gr) } \\
\hline & & Keju & Durian & $\begin{array}{c}\text { Cokelat } \\
\text { Oreo }\end{array}$ & Original & Keju & Kismis & Original \\
\hline 1. & $\begin{array}{l}\text { Tepung } \\
\text { Terigu }\end{array}$ & 8,33 & 8,33 & 8,33 & 8,33 & 42,86 & 42,86 & 42,86 \\
\hline 2. & Susu & 8,33 & 8,33 & 8,33 & 8,33 & 42,86 & 42,86 & 42,86 \\
\hline 3. & $\begin{array}{l}\text { Kelapa } \\
\text { Muda }\end{array}$ & 22,22 & 22,22 & 22,22 & 22,22 & 114,29 & 114,29 & 114,29 \\
\hline 4. & Telur & 5,33 & 5,33 & 5,33 & 5,33 & 27,43 & 27,43 & 27,43 \\
\hline 5. & Mentega & 8,33 & 8,33 & 8,33 & 8,33 & 42,86 & 42,86 & 42,86 \\
\hline 6. & Gula & 19,44 & 19,44 & 19,44 & 19,44 & 100 & 100 & 100 \\
\hline 7. & Garam & 0,42 & 0,42 & 0,42 & 0,42 & 2,14 & 2,14 & 2,14 \\
\hline 8. & Vanili & 0,17 & 0,17 & 0,17 & 0,17 & 0,86 & 0,86 & 0,86 \\
\hline 9. & $\begin{array}{l}\text { Tepung } \\
\text { Maizena }\end{array}$ & 12,5 & 12,5 & 12,5 & 12,5 & 64,27 & 64,27 & 64,27 \\
\hline 10. & Keju & 2,5 & - & - & - & 12,86 & - & - \\
\hline 11. & Durian & - & 11,11 & - & - & - & - & - \\
\hline 12. & $\begin{array}{c}\text { Cokelat } \\
\text { Oreo }\end{array}$ & - & - & 2,44 & - & - & - & - \\
\hline 13. & Kismis & - & - & - & 2,78 & - & 14,29 & 14,29 \\
\hline 14. & Kenari & - & - & - & 2,78 & - & - & 14,29 \\
\hline 15. & $\begin{array}{l}\text { Kayu } \\
\text { Manis }\end{array}$ & - & - & - & 1,39 & - & - & 7,14 \\
\hline
\end{tabular}

(Sumber: Dedy Sutrisno, 2016) 
Tabel 5 : Tabel Jumlah Pesanan

\begin{tabular}{|c|l|c|}
\hline No. & \multicolumn{1}{|c|}{ Varian Klappertart } & Jumlah Pesanan (buah) \\
\hline 1. & Klappertart Basah Keju & 50 buah \\
\hline 2. & Klappertart Basah Durian & 50 buah \\
\hline 3. & Klappertart Basah Cokelat Oreo & 50 buah \\
\hline 4. & Klappertart Basah Original & 50 buah \\
\hline 5. & Klappertart Kering Keju & 5 buah \\
\hline 6. & Klappertart Kering Kismis & 5 buah \\
\hline 7. & Klappertart Kering Original & 5 buah \\
\hline
\end{tabular}

(Sumber: Dedy Sutrisno, 2016)

\subsubsection{Pemodelan Matematika}

Variabel Keputusan:

$x_{1}=$ Banyaknya varian Klappertart Basah Keju yang diproduksi.

$x_{2}=$ Banyaknya varian Klappertart Basah Durian yang diproduksi.

$x_{3}=$ Banyaknya varian Klappertart Basah Cokelat Oreo yang diproduksi.

$x_{4}=$ Banyaknya varian Klappertart Basah Original yang diproduksi.

$x_{5}=$ Banyaknya varian Klappertart Kering Keju yang diproduksi.

$x_{6}=$ Banyaknya varian Klappertart Kering Kismis yang diproduksi.

$x_{7}=$ Banyaknya varian Klappertart Kering Original yang diproduksi.

\subsubsection{Penyelesaian Metode Simpleks Dengan Program QM For Windows}

Masalah di atas dapat diselesaikan dengan menggunakan metode simpleks secara manual dan juga menggunakan software QM For Windows dengan hasil yang di tunjukkan pada Gambar 1.

\begin{tabular}{||r|r|r|}
\hline Variable & Status & Value \\
\hline X1 & Basic & 50 \\
\hline X2 & Basic & 50 \\
\hline X3 & Basic & 50 \\
\hline X4 & Basic & 50 \\
\hline X5 & Basic & 5 \\
\hline X6 & Basic & 5 \\
\hline X7 & Basic & 5 \\
\hline slack 1 & Basic & 1691,1 \\
\hline slack 2 & Basic & 1241,1 \\
\hline slack 3 & Basic & 1841,65 \\
\hline slack 4 & Basic & 922,55 \\
\hline slack 5 & Basic & 1691,1 \\
\hline slack 6 & Basic & 2612 \\
\hline slack 7 & Basic & 133,9 \\
\hline slack 8 & Basic & 28,1 \\
\hline slack 9 & Basic & 1635,65 \\
\hline slack 10 & Basic & 170,7 \\
\hline slack 11 11 & Basic & 444,5 \\
\hline slack 12 & Basic & 148 \\
\hline slack 13 & Basic & 218,1 \\
\hline slack 14 & Basic & 289,55 \\
\hline
\end{tabular}




\begin{tabular}{||l|r|r|}
\hline slack 15 & Basic & 394,8 \\
\hline surplus 16 & NONBasic & 0 \\
\hline surplus 17 & NONBasic & 0 \\
\hline surplus 18 & NONBasic & 0 \\
\hline surplus 19 & NONBasic & 0 \\
\hline surplus 20 & NONBasic & 0 \\
\hline surplus 21 & NONBasic \\
\hline surplus 22 & Basic \\
\hline slack 23 & Basic & 0 \\
\hline slack 24 & Basic \\
\hline slack 25 & Basic & 22 \\
\hline slack 26 & Basic & 22 \\
\hline slack 27 & Basic & 22 \\
\hline slack 28 & Basic & 2 \\
\hline slack 29 & & 2 \\
\hline Optimal Value $(Z)$ & & 2 \\
\hline
\end{tabular}

Gambar 1 : Hasil perhitungan metode simpleks menggunakan software QM For Windows.

\subsection{Pembahasan}

\subsubsection{Analisis Biaya Bahan Baku Pembuatan Klappertart oleh UKM Najmah Klappertart}

Total biaya produksi klappertart berdasarkan bahan baku yang dikeluarkan oleh UKM Najmah Klappertar diperoleh dari hasil perhitungan antara banyaknya produksi klappertart tiap hari dikalikan dengan biaya produksi klappertart per buah. Banyak klappertart yang diproduksi sama dengan banyak klappertart yang dipesan karena dalam hal ini perusahaan tidak melakukan penyimpanan hasil produksi. Berikut adalah daftar banyaknya klappertart yang diproduksi tiap varian klappertart yang diteliti dalam skripsi ini.

Tabel 6 : Produksi Klappertart

\begin{tabular}{|l|l|l|}
\hline No. & Varian Klappertart & Jumlah Pesanan \\
\hline 1. & Klappertart Basah Keju & 50 buah \\
\hline 2. & Klappertart Basah Durian & 50 buah \\
\hline 3. & Klappertart Basah Cokelat Oreo & 50 buah \\
\hline 4. & Klappertart Basah Original & 50 buah \\
\hline 5. & Klappertart Kering Keju & 5 buah \\
\hline 6. & Klappertart Kering Kismis & 5 buah \\
\hline 7. & Klappertart Kering Original & 5 buah \\
\hline
\end{tabular}

Jadi total biaya produksi klappertart berdasarkan bahan baku yang dikeluarkan oleh UKM Najmah Klappertart adalah sebesar (Rp.3.216,36 x 50)+(Rp. 3.244,14 x 50)+ (Rp. 2.994,14 x 50) + (Rp. 3.435,53 x 50) + (Rp. 18.111,14 x 5) + (Rp. 19.968,28 x 5) + (Rp. 19.238,28 x 50) = Rp. 931.097,-- 
3.2.2. Analisis Biaya Bahan Baku Pembuatan Klappertart dengan Metode Simpleks Berbantu Software QM For Windows.

Analisis total biaya produksi berdasarkan bahan baku klappertart hasil perhitungan Metode Simpleks menggunakan QM For Windows dapat dilihat pada outputnya. Output yang dihasilkan oleh program QM For Windows dalam menyelesaikan model linier diatas memberikan keterangan bahwa $\mathrm{Z}_{\mathrm{Min}}=931.097$ dimana:

$x_{1}=50$

$x_{2}=50$

$x_{3}=50$

$x_{4}=50$

$x_{5}=5$

$x_{6}=5$

$x_{7}=5$

Hasil perhitungan dari software QM For Windows menghasilkan biaya optimal sebesar Rp. 931.097,- dengan memproduksi masng-masing varian klappertart seperti di bawah ini:

Klappertart Varian Basah Keju $=50$ buah

Klappertart Varian Basah Durian $=50$ buah

Klappertart Varian Basah Oreo $=50$ buah

Klappertart Varian Basah Original $=50$ buah

Klappertart Varian Kering Keju $=5$ buah

Klappertart Varian Kering Kismis $=50$ buah

Klappertart Varian Original $=5$ buah

Setelah dilakukan perbandingan biaya bahan baku pembuatan klappertart yang dilakukan oleh UKM Najmah Klappertart dengan perhitungan menggunakan metode simpleks berbantu software QM For Windows, ternyata memberikan total biaya produksi yang sama. Jadi dapat dikatakan bahwa biaya produksi klappertart berdasarkan bahan baku pembuatannya sudah optimal. Hasil ini dapat terjadi disebabkan karena UKM Najmah Klappertart memproduksi sesuai dengan jumlah pesanan yang ada.

\subsubsection{Analisis Sensitivitas}

Analisis sensitivitas dilakukan untuk mengetahui tingkat kepekaan model setelah hasil optimal ada. Pada analisis sensitivitas dapat melihat pengaruh dari selang kepekaan yang terdiri dari batas minimum (allowable decrease atau lower bound) yaitu batas dari penurunan kendala yang tidak mempengaruhi model sedangkan batas maksimum (allowable increase atau upper bound) yaitu batas kenaikan kendala yang tidak merubah model. Jika perubahan masih dalam selang, maka tidak akan terjadi perubahan pada kombinasi produk optimal (Ai Murhayati dkk). 
Analisis sensitivitas terhadap nilai koefisien fungsi tujuan merupakan selang perubahan nilai koefisien yang masih diizinkan. Selang perubahan tersebut dapat dilihat pada Gambar 2.

\subsubsection{Analisis Sensitivitas Nilai Koefisien Fungsi Tujuan}

\begin{tabular}{|l|r|r|r|r|r|}
\hline Variable & Value & Reduced Cost & Original Val & Lower Bound & Upper Bound \\
\hline X1 & 50 & 0 & 3216,36 & 0 & Infinity \\
\hline X2 & 50 & 0 & 3244,14 & 0 & Infinity \\
\hline X3 & 50 & 0 & 2994,14 & 0 & Infinity \\
\hline X4 & 50 & 0 & 3435,53 & 0 & Infinity \\
\hline X5 & 5 & 0 & 18111,14 & 0 & Infinity \\
\hline X6 & 5 & 0 & 19968,28 & 0 & Infinity \\
\hline X7 & 5 & 0 & 19238,28 & 0 & Infinity \\
\hline
\end{tabular}

Gambar 2 : Analisis Sensitivitas Nilai Koefisien Fungsi Tujuan

Pada Gambar 2 diketahui bahwa nilai $x_{1}=50, x_{2}=50, x_{3}=50, x_{4}=50, x_{5}=5, x_{6}=$ $5, x_{7}=5$. Nilai dari Reduced Cost sangat berarti jika variabel keputusan yang bersangkutan bernilai 0 (nol), karena fungsi dari Reduced Cost adalah untuk menunjukkan berapa banyak biaya per unit dari suatu variabel dapat dikurangi agar solusi optimal yang diperoleh dari variabel tersebut bernilai positif. Berdasarkan output diatas, nilai variabel keputusannya tidak ada yang bernilai nol, sehingga Reduced Cost juga bernilai nol.

Allowable Decrease (Lower Bound) semua variabel menunjukkan angka 0 , artinya biaya produksi dari ketujuh varian klappertart tersebut tidak dapat diturunkan lagi karena akan mejadikan solusi tidak optimal lagi. Apabila pada tabel Lower Bound bernilai lebih dari nol maka batas penurunan biaya produksi yang diizinkan adalah sebesar angka tersebut. Sedangkan pada Allowable Increase (Upper Bound) untuk semua variabel menunjukkan Infinity, batasan kenaikan koefisien biaya produksi yang tidak terhingga tidak akan mempengaruhi biaya optimal, namun apabila meningkatkan biaya yang tinggi akan menyebabkan harga jual yang tinggi kepada konsumen. 


\subsubsection{Analisis Sensitivitas Nilai Koefisien Fungsi Kendala}

\begin{tabular}{|c|c|c|c|c|c|}
\hline Constraint & Dual Value & Slack/Surplus & Original Val & Lower Bound & Upper Bound \\
\hline Constraint 1 & 0 & 1691,1 & 4000 & 2308,9 & Infinity \\
\hline Constraint 2 & 0 & 1241,1 & 3600 & 2358,9 & Infinity \\
\hline Constraint 3 & 0 & 1841,649 & 8000 & 6158,35 & Infinity \\
\hline Constraint 4 & 0 & 922,5499 & 2400 & 1477,45 & Infinity \\
\hline Constraint 5 & 0 & 1691,1 & 4000 & 2308,9 & Infinity \\
\hline Constraint 6 & 0 & 2612 & 8000 & 5388 & Infinity \\
\hline Constraint 7 & 0 & 133,9 & 250 & 116,1 & Infinity \\
\hline Constraint 8 & 0 & 28,1 & 75 & 46,9 & Infinity \\
\hline Constraint 9 & 0 & 1635,65 & 5100 & 3464,35 & Infinity \\
\hline Constraint 10 & 0 & 170,7 & 360 & 189,3 & Infinity \\
\hline Constraint 11 & 0 & 444,5 & 1000 & 555,5 & Infinity \\
\hline Constraint 12 & 0 & 148 & 270 & 122 & Infinity \\
\hline Constraint 13 & 0 & 218,1 & 500 & 281,9 & Infinity \\
\hline Constraint 14 & 0 & 289,55 & 500 & 210,45 & Infinity \\
\hline Constraint 15 & 0 & 394,8 & 500 & 105,2 & Infinity \\
\hline Constraint 16 & $-3216,36$ & 0 & 50 & 0 & 72 \\
\hline Constraint 17 & $-3244,14$ & 0 & 50 & 0 & 72 \\
\hline Constraint 18 & $-2994,14$ & 0 & 50 & 0 & 72 \\
\hline Constraint 19 & $-3435,53$ & 0 & 50 & 0 & 72 \\
\hline Constraint 20 & $-18111,14$ & 0 & 5 & 0 & 7 \\
\hline Constraint 21 & $-19968,28$ & 0 & 5 & 0 & 7 \\
\hline Constraint 22 & $-19238,28$ & 0 & 5 & 0 & 7 \\
\hline NEW Constraint & 0 & 22 & 72 & 50 & Infinity \\
\hline NEW Constraint & 0 & 22 & 72 & 50 & Infinity \\
\hline NEW Constraint & 0 & 22 & 72 & 50 & Infinity \\
\hline NEW Constraint & 0 & 22 & 72 & 50 & Infinity \\
\hline NEW Constraint & 0 & 2 & 7 & 5 & Infinity \\
\hline NEW Constraint & 0 & 2 & 7 & 5 & Infinity \\
\hline NEW Constraint & 0 & 2 & 7 & 5 & Infinity \\
\hline
\end{tabular}

Gambar 3 : Analisis Sensitivitas Nilai Koefisien Fungsi Tujuan

Pada Gambar 3 memperlihatkan nilai penurunan dan kenaikan koefisien fungsi kendala yang diizinkan. Bahan baku yang berlebih persediaannya, besar batas penurunan yang diizinkan adalah sebesar nilai slack/surp/us-nya, sehingga batas minimum ketersediaan bahan baku Klappertart sebesar 2308,9 gram untuk baku tepung terigu, 2308,9 gram untuk susu, 6158,35 gram untuk kelapa muda, 1477,45 gram untuk telur, 2308,9 untuk mentega, 5388 gram untu gula pasir, 116,1 gram untuk garam, 46,9 gram untuk vanili, 3464,35 gram untuk tepung maizena, 189,3 gram untuk keju, 555,5 gram untuk durian, 122 gram untuk coklat oreo, 281,9 gram untuk kismis, 210,45 gram untuk kenari dan 105,2 gram untuk batas minimum kayu manis.

Batas peningkatan kendala pemesanan untuk ketujuh varian memiliki batas peningkatan sebesar 0 . Batas maksimum pemesanan yang masih dapat dipenuhi UKM yang diizinkan masing-masing sebesar 72 buah untuk Klappertart Varian Basah Keju, Klappertart Varian Basah Durian, Klappertart Varian Basah Oreo, Klappertart Varian Basah Original dan masing-masing 7 buah Klappertart Varian Kering Keju, Klappertart Varian Kering Kismis dan Klappertart Varian Original.

Batas peningkatan kendala kapasitas untuk ketujuh varian memiliki batas peningkatan masing-masing sebesar 50 buah untuk Klappertart Varian Basah Keju, Klappertart Varian Basah Durian, Klappertart Varian Basah Oreo, Klappertart Varian Basah Original dan masingmasing 5 buah Klappertart Varian Kering Keju, Klappertart Varian Kering Kismis dan 
Klappertart Varian Original. Sedangkan pada Allowable Increase (Upper Bound) untuk semua varian menunjukkan Infinity.

Upper Bound pada batasan kapasitas memberikan hasil Infinity, tidak berarti bahwa perusahan dapat menyediakan kapasitas dengan tidak terbatas, namun UKM tetap memiliki batas-batas tertentu untuk dapat menambah kapasitas produksi sesuai dengan jumlah bahan baku yang ada.

\section{KESIMPULAN}

Berdasarkan hasil penelitian dan pembahasan yang diuraikan menunjukan bahwa perbandingan biaya bahan baku pembuatan klappertart yang dilakukan oleh UKM Najmah Klappertart dengan perhitungan menggunakan metode simpleks ternyata ,menghasilkan total biaya produksi yang sama. Hasil perhitungan dari metode simplek berbantu software QM For Windows memberikan biaya optimal sebesar Rp.931.097,- dengan memproduksi Klappertart Varian Basah Keju = 50 buah, Klappertart Varian Basah Durian $=50$ buah, Klappertart Varian Basah Oreo $=50$ buah, Klappertart Varian Basah Original $=50$ buah, Klappertart Varian Kering Keju $=5$ buah, Klappertart Varian Kering Kismis $=50$ buah dan Klappertart Varian Original $=5$ buah. Jadi, dapat disimpulkan bahwa biaya produksi klappertart berdasarkan bahan baku pembuatannya pada UKM Najmah Klappertart sudah optimal.

Berdasarkan analisis sensitivitas tiap varian, untuk ketersediaan bahan baku Klappertart sebesar 2308,9 gram untuk baku tepung terigu, 2308,9 gram untuk susu, 6158,35 gram untuk kelapa muda, 1477,45 gram untuk telur, 2308,9 untuk mentega, 5388 gram untu gula pasir, 116,1 gram untuk garam, 46,9 gram untuk vanili, 3464,35 gram untuk tepung maizena, 189,3 gram untuk keju, 555,5 gram untuk durian, 122 gram untuk coklat oreo, 281,9 gram untuk kismis, 210,45 gram untuk kenari dan 105,2 gram untuk batas minimum kayu manis. 


\section{DAFTAR PUSTAKA}

[1] Ai, Nurhayati, Optimalisasi Produksi Menggunakan Model Linear Programming (Studi Kasus: Usaha Kecil Menengah Kue Seprong).

[2] Harsanto, Budi, Naskah Tutorial QM For Windows.

[3] Sutrisno, Dedy, Aplikasi Metode Goal Programming Pada Perencanaan Produksi Klappertaart (Studi Kasus: Usaha Kecil Menengah (UKM) Najmah Klappertaart, Jl. Nangka Palu). Skripsi (23-31), 2016, Palu: Program Studi Matematika Jurusan Matematika Fakultas Matematika dan IImu Pengetahuan Alam Universitas Tadulako. 